\title{
DIAGNOSTIC OF WATER VAPOR ADSORPTION MOLAR HEAT AND ACCUMULATION AT BUBBLE SURFACE DURING AERATION TREATMENT IN SATURATION PERIOD
}

\author{
Miladin Ševaljević* \\ Technical School, Zrenjanin, Serbia \\ Stojan Simić \\ Faculty of Mechanical Engineering, University of Sarajevo, Bosnia and Hercegovina \\ Miroslav Stanojević \\ Faculty of Mechanical Engineering, University of Belgrade, Serbia \\ Milan Pavlović \\ Technical faculty"Mihajlo Pupin"in Zrenjanin, Serbia \\ Mirjana Ševaljević \\ Technical faculty"Mihajlo Pupin“in Zrenjanin, Serbia
}

Diagnostics of adsorbed water vapor molar heat and accumulation at bubble surface during refinery waste water aeration treatment with membrane distributor was performed, on the basis of experimentally measured air temperature and pressure on input and exit and measured stationary oxygen content after saturation period. The working hypothesis is that electromotor and compressor favor the consumption of water vapor adsorption heat at bubbles surfaces and the relaxation with active centers transport work, according to II law of thermodynamic. During air over-pressure relaxation, active centers enable the couple of prevented exothermic hydration and favored endothermic processes and water vapor accumulation up to catalyst final titration points in zone of condensation, precipitatation, vaporization, nitrification/denitrification and biological slime that can cause diffuser fouling and scalling. Diagnostics results for the all 15 examined systems with the same membrane diffuser and various combination of process parameters, $c-h-q$ : without and with added motor oil, $c=0 \mathrm{mg} / \mathrm{l} 5 \mathrm{mg} / \mathrm{l}$ and $10 \mathrm{mg} / \mathrm{l}$, with two heights of water column, $h=1 \mathrm{~m}$ and $2 \mathrm{~m}$ and with three air flows, $q=2 \mathrm{~m}^{3} / \mathrm{h}, 6 \mathrm{~m}^{3} / \mathrm{h}$ and $10 \mathrm{~m}^{3} / \mathrm{h}$ verified the linear functional dependence of indicator of proper process condition, i.e. experimental determined oxygen saturation degree on water vapor accumulation $\left(R^{2}=0.766\right)$.

Key words: Water vapor, Vaporization, Saturation, Oxygen, Molarity, Heating, Bubbles, Air, Adsorption, Accumulation

\section{INTRODUCTION}

Aeration, i.e. mass transfer of air components from gas to liquid phase explains two films theory in contact surface on the side of air and on the side of water. Fine pore diffusers are subject to two major disadvatages: a) fouling if not cleaned periodically and b) decrease in oxygen transfer efficiency by dissolved surfactants. The aeration have higher energy demand and can require periodically cleaning if water accumulation at bubble surfaces decrease oxygen saturation degree in aerated wastewater relating to clean water in standard conditions, depending on [01, 02]: a) waste water caracteristics (COD, BOD, and $\left.\mathrm{NH}_{3} / \mathrm{N}\right)$

b) precipitation in membrane pores and of particles from air as well as of solid suspended and dissolved matter of hydroxide, carbonate, sulfate, phosphate, biofilm and surfactants from liquid phase.

In our previous papers it was obtained oxygen saturation degree is indicator of proper process condition, that controls the slowest successive transfer step of the complex air oxygen transfer process through bubble surface [03]: 
- with thermal collisions on the side of gas bubble, in the aerated water with good oxygen solubility

- with diffusion on the side of liquid, in the aerated water with small oxygen solubility

- or with the both mechanisms.

At the oxygen concentration defined according to Henry law in the accumulated clean water layer oxygen stationary electrochemical potential controls oxygen volumetric transport coefficient [04]. Also, on the basis of linear functional dependence of oxygen transport efficiency on oxygen transport coefficient and drift rate constant ratio, for the all examined systems $\left(R^{2}=0.9814\right)$, the molar oxygen transfer work from gas bubble in unit liquid volume was determined, at the equal change of oxygen transport coefficient with drift rate constant change [04]:

$$
W^{\theta}\left(\mathrm{O}_{2}\right)=22410 \mathrm{~kJ} / \mathrm{mol}
$$

It corresponds to the sum of water vapor critical pressure, gas hydrogen molar dissociation work and gas oxygen dissolution enthalpy:

$$
W^{\theta}\left(\mathrm{O}_{2}\right)=p_{c r, \mathrm{H}_{2} O}+A_{\text {dissoc }}^{\theta}\left(H_{2} / 2 H\right)+\Delta_{\text {dissol }} H^{\theta}\left(\mathrm{O}_{2}\right)(2)
$$

Water vapor at its critical pressure is dense nonpolar gas [05]. Condensed drops at critical pressure dissolve non-polar gases oxygen and nitrogen in concentrations defined according to Henry law i.e. in electrochemical equilibrium state. Gas components, $\mathrm{CO}_{2}$ and $\mathrm{CH}_{4}$ are miscible in all ratios and organic compounds as benzene and metilen-chloride are strongly soluble in condensate [06]. Water density $\left(0.1 \mathrm{~g} / \mathrm{cm}^{3}\right)$ is strongly dependent on temperature and pressure with variations for more than one order of magnitude, relating to liquid water in standard conditions. In subcritical and supecritical conditions, $\mathrm{p}_{\mathrm{cr}}=22.1$ $\mathrm{MPa}, t_{c r, \mathrm{H}_{2} \mathrm{O}}=374.2^{\circ} \mathrm{C}$ dominate the next processes [07]:

- couple catalytic oxidation and hydrolysis of air components and organic compounds, that contain hetero-atoms, where fast phases separations are possible, as well as completely aggregation of inorganic salts [08, 09];

- electron kinetic energy relaxation in vaporization processes through hydrated layer in supercritical range with energy bonds of water vapor and adsorbed impurities, that control intermolecular forces in bubble surface [10];

- Water ions product decreasing 10-23
$\mathrm{Kw}=\left[\mathrm{H}^{+}\right]\left[\mathrm{OH}^{-}\right][11 /]$ and water vapor diffusivity increasing, during adiabathic compression favored with water ions neutralization [12].

In our previous papers it was obtained the quasisteady processes of oxygen in isentropic conditions on gas air input control hydrogen evolution overpotentials, as well as gas oxygen chemical potential in isochoric liquid phase and isobaric transport work at air exit, keeping the stationary state of:

- oxygen adsorption equilibrium constant at the equal speciphic adsorption and desorption velocity, according to Langmuire adsorption isotherm and liquid water entropy, $\mathrm{S}^{\theta}\left(\mathrm{H}_{2} \mathrm{O}\right)_{1}$ decreasing in water column $2 \mathrm{~m}$ high and increasing in water column $1 \mathrm{~m}$ high for the same value $1 / 2 \mathrm{~S}^{\theta}\left(\mathrm{H} / \mathrm{H}^{-}\right)$aq [13];

- electron flux in reaction layer of dehydrated hydrophobic components adsorbed acc. to Gibbs-adsorption isotherm during couple with hydrated oxygen desorbtion from hydrophilic components [14];

- temperature that enable the balance between isothermal transport work of gas electron on active centers, $A_{e / O 2}=R \cdot T_{e} \ln p / p_{a}$ with electron hydration work of , $A_{\text {eaq }}=C_{V}\left(T_{\text {eaq }}\left(C^{*}\right)-T_{L}\right)[14]$;

- hydration layer relative electric permittivity of specific adsorbed, super-oxide anion, $\varepsilon_{r}\left(\mathrm{O}_{2} / \mathrm{O}_{2}^{-}\right)_{\mathrm{aq}}=10.3$ that controls oxygen surface polarization and real energy efficiency of oxygen transport [04].

These processes indicate to active centers transport work, that enables the couple of prevented exothermic hydration with endothermic vaporization process [15].

The working hypothesis is that electromotor and compressor on air input prevent liquid water heating due to the couple with endothermic relaxation process on active centers in gas bubble surface, according to II law of thermodynamic, and successive accumulation in zone of phase transition up to catalytic impurity final titration point.

The verification of diagnostic method could enable the functional dependence of indicator of proper process condition in the slowest relaxation step in the each examined system, i.e. of oxygen saturation degree on the water vapor accumulation [03]. 


\section{DIAGNOSTICS OF WATER VAPOR MOLAR HEAT AND CATALYST ACCUMULATION USING II THERMODYNAMIC LAW}

According to the previous results [14] water vapor work at critical pressure in gas bubble with specific surface, $a=A / V$ in liquid unit volume, with equal probability in the all directions (Paskal law) controls oxygen molar transfer work consumed from electromotor and compressor defined in Eq. (1) and Eq. (2):

$$
p_{c r, H_{2} O}=W^{\theta}\left(O_{2}\right)-\left(A_{\text {dissoc }}\left(H_{2} / 2 H\right)+\Delta_{\text {dissol }} H^{\theta}\left(O_{2}\right)\right)
$$

Stationary air flow and stationary air temperature at air input, $T_{G}$ as well as at exit from liquid in rounding air, $T_{R}$ enable isentropic adiabatic relaxation processes. They prevent liquid water over-heating and favor evaporation at stationary entropy, $\mathrm{S}^{\theta}\left(\mathrm{H}_{2} \mathrm{O}\right)_{\mathrm{g}}=188.7 \mathrm{~J} / \mathrm{molK}$, or phase transition in the presence of the substance with equal entropy at bubble surface, for example $\mathrm{S}^{\theta}(\mathrm{AlH})_{\mathrm{g}}=187.7 \mathrm{~J} / \mathrm{molK}$.

After air input and before output from liquid, isochoric-isentropic relaxation processes keep constant the ratio between pressure and temperature:

$$
\frac{p^{\prime}}{T_{R}}=\frac{p_{G}}{T_{G}}
$$

The combination with bubble transport work through liquid phase, at constant temperature:

$$
V_{e x} p_{e x}=p^{\prime} V_{g}
$$

defines the transport work through contact surface of unit volume on input and output with the equation of ideal gas state:

$\frac{V_{e x} p_{e x}}{T_{R}}=\frac{p_{G} V_{G}}{T_{G}}=R$

At critical water vapor pressure, a couple of exothermic heating and favored endothermic cooling processes determine water vapor molar adsorption heat:

$$
\left(\lambda_{\text {ex }}^{\theta}-\lambda_{\text {end }}^{\theta}\right)=\Sigma \lambda^{\theta}{ }_{\text {acc }}
$$

Then in accumulation cycle water vapor adsorption heat causes molar water vapor volume change $V^{\theta}=\left(V_{0}^{;}-V\right)$, that along with air over-pressure controlls the efficiency of active centers transport work at bubble surfaces between heater and cooler, according to II thermodynamic law (Carnoo cycle):

$$
\frac{A_{\text {ex }}+A_{\text {end }}}{\sum \lambda_{\text {acc }}}=\frac{d T}{T_{g}}
$$

where:

$$
A_{e x}=p n\left(V_{0}-V_{0}\right)
$$

$$
A_{\text {end }}=-(p-d p) n\left(V_{0},-V_{0}\right)
$$

The combination gives Clausius-Klapejron equation:

$\frac{\left(V_{0}-V\right) d p}{\Sigma \lambda^{\theta}{ }_{\text {acc }}}=\frac{d T}{T_{g}}$

It enables the diagnostics of:

a) of adsorbed water vapor molar heat in period of couple catalytic titration:

$$
\Sigma \lambda^{\theta}{ }_{\text {acc }}=\frac{T_{g} V^{\theta}}{\mu_{J . T}}
$$

where:

$$
\Sigma \lambda^{\theta}{ }_{\text {acc }}=\frac{\sum \lambda_{\text {exot }+ \text { endot. }}}{n_{\text {acc }}}
$$

and Joules - Thomson coefficient in adiabathic process:

$$
\mu_{J . T .}=\left(\frac{d T}{d p}\right)_{H=c o n s t}=\frac{\left(T_{R}-T_{g}\right)}{\left(p-p_{a}\right)}
$$

b) Catalytic water vapor accumulation enables air over-pressure the relaxation, $p-p_{a}$ at bubble entered in water:

$$
\Delta c_{a c c}=\frac{p-p_{a}}{\sum \lambda^{\theta}{ }_{\text {hyd/deh }}}
$$

Liquid heating prevents oxygen surface free energy that controls:

- electron transition activation energy, $\mathrm{E}_{\mathrm{e.a}}$ :

$F E^{\theta}{ }_{e, a}=p_{e} V_{e}^{\theta}$

- in isentropic relaxation processes :

$\frac{p_{e} V_{e}^{\theta}}{\varepsilon_{0} T_{e}}=\frac{p_{g} V_{g}^{\theta}}{\varepsilon T_{g}}$

- and at isobaric hydrogen evolution over-potential, $n p$ in gas buble with radius, $d_{B}$ determined according to Born definition of intermolecular energy bond, that enable couple hydration process [16]:

$$
d_{B}=\frac{0,7}{\eta_{p}} n m
$$

Radius of condensed drop in bubble surface controlled with surface tension on the side of liquid acc. to Kelvin equation, $d_{k}$ enable the balance with electric field strengths of in the hydration layer on the side of gas phase:

$$
\frac{F E_{e, a}}{\varepsilon_{0} \cdot d_{B}}=\frac{\Delta G}{\varepsilon \cdot d_{K}}
$$


Then the hydration layer of catalytic active centers defines relative electric permittivity, $\varepsilon_{\mathrm{r}}$ :

$\varepsilon_{r, a . c .}=\frac{d_{B}\left(\eta_{p}\right)}{d_{K}}$

In our previous paper average relative electric permittivities of active centers in the examined systems are calculated on the basis of Born and Kelvin diameter of hydration layer, on the side of gas and liquid phase [16]:

$\varepsilon_{r, \text { hyd/deh. }}=4,04$

The experimentally obtained average ratio for the examined aeration regimes:

$$
\frac{p_{g}}{T_{g, K}}=424,54 \mathrm{~J} / \mathrm{K}
$$

with variations $3-5 \%$ and relative electric permittivity enable to caculate the stationary value of transient electron entropy, that corresponds to catalyst entropy change and after combination with Eq. (16) and Eq. (17) defines the activation energy of electron transition:

$\frac{p_{g}}{T_{g},_{K} \varepsilon_{r}}=\frac{\mathrm{F} \Delta \mathrm{E}_{\mathrm{e}, \mathrm{a}}^{\theta}}{T_{e}}=105 \mathrm{~J} / \mathrm{molK}$

According to the Table datas [17], the average stationary liquid temperature, $\mathrm{T}_{\mathrm{L}}=287 \mathrm{~K}$ with variations up to $11 \%$ [14] keeps the stationary, entropy of dissolved gas oxygen:

$S^{\theta}\left(O_{2}\right)_{a q}=\frac{\Delta G^{\theta}\left(O_{2} / O_{2}^{-}\right)_{a q}}{T_{l}}=110,9 \mathrm{~J} / \mathrm{molK}$

and of hydrated hydride:

$S^{\theta}\left(\mathrm{H}^{-}\right)_{\text {aq }}=5,9 \mathrm{~J} / \mathrm{molK}$

The difference between these values corresponds to the result obtained in Eq. (22), that indicates to electron transition between specific adsorbed superoxide and hydride anion and gas oxygen and hydrogen keeping the stationary pressure, gas temperature and electric permittivity of hydration layer at air input:

$$
\begin{aligned}
& O_{2}+\left(\mathrm{H}^{-}\right)_{\text {aq }}=\left(\mathrm{O}_{2}^{-}\right)_{\mathrm{aq}}+\mathrm{H} \\
& S^{\theta}\left(\mathrm{O}_{2}\right)_{\text {aq }}-S^{\theta}\left(\mathrm{H}^{-}\right)_{\mathrm{aq}}=\frac{p}{T_{g} \varepsilon_{r}}
\end{aligned}
$$

Hydrated oxygen and hydrated hydride entropy indicate:

a) to the resonance with colloid particles entropy, $\mathrm{S}^{\ominus}\left(\mathrm{As}_{2} \mathrm{O}_{3, \mathrm{c}}\right)=\mathrm{S}^{\theta}\left(\mathrm{Al}_{4} \mathrm{C}_{3}\right)_{\mathrm{c}}=105 \mathrm{~J} / \mathrm{moK}$, or with dissolved metal ions on $\mathrm{Zn}$ anode $\mathrm{S}^{\theta}\left(\mathrm{Zn}^{2+}\right)=-106.5 \mathrm{~J} / \mathrm{moK}$;

b) along with the couple that keep constant liquid water entropy:

- in flocculation, aggregation and sedimentation processes:

$\mathrm{S}^{\theta}\left(\mathrm{H}_{2} \mathrm{O}\right)_{1}=\mathrm{S}^{\theta}\left(\mathrm{A}_{\mathrm{s} 2} \mathrm{O}_{3, \mathrm{c}}, \mathrm{Al}_{4} \mathrm{C}_{3}\right)+\mathrm{S}^{\theta}\left(\mathrm{HPO}_{4}{ }^{2-}\right)=$ $69.9 \mathrm{~J} / \mathrm{molK}$

- as well as in chemical and electrochemical electron trasnsitions: $S^{\theta}\left(H_{2} O\right) I=-\left(S^{\theta}\left(A_{s}, F_{e}, C_{u}, M_{g}, T, W, B_{N}\right)_{g}\right.$ $\left.-S^{\theta}\left(Z_{n}{ }^{2+}\right)\right)=69.9 \mathrm{~J} / \mathrm{molK}$,

where:

$\mathrm{S}^{\theta}\left(\mathrm{HPO}^{2-}\right)=-36 \mathrm{~J} / \mathrm{molK}^{-}, \mathrm{S}^{\theta}($ As $) \mathrm{c}$, metal $=35$ $\mathrm{J} / \mathrm{molK}$ and $S^{\theta}\left(F_{e}, C_{u}, B N M g, T_{i}, W\right) c=27-33$ $\mathrm{J} / \mathrm{molK}$.

\section{EXPERIMENT}

The choosed air distributor disk "Gummy-Jaeger" type HD 340 from material EPDM (ethilenpropilen-dimer) was the same in the examined 15 combination of aeration process parameters, c-h-q:

- without and with added waste motor oil, $\mathrm{c}=0 \mathrm{mg} / \mathrm{l}, \quad 5 \mathrm{mg} / \mathrm{l}$ and $10 \mathrm{mg} / \mathrm{l}$;

- with two heights of water column, $h=1 \mathrm{~m}$ and $2 \mathrm{~m}$;

- and with three air flows, $q=2 \mathrm{~m}^{3} / \mathrm{h}$, $6 \mathrm{~m}^{3} /$ hand $10 \mathrm{~m}^{3} / \mathrm{h}$.

In the discontinual aeration process viscous waste motor oil was used, SAE $15 \mathrm{~W}-40$, with viscosities index $132.0 \mathrm{~mm}^{2} / \mathrm{s}$, temperature of inflammation, $231.0^{\circ} \mathrm{C}$, TAN, $3.18 \mathrm{mg} \mathrm{KOH} / \mathrm{g}$ i TBN9.73 $\mathrm{mg} \mathrm{KOH} / \mathrm{g}$ and contents of: $0.039 \% \mathrm{Z}_{\mathrm{n}}, 0.310 \%$ $\mathrm{C}_{\mathrm{a}}, 13.4 \mathrm{ppm} \mathrm{F}_{\mathrm{e}}, 4.11 \mathrm{ppm} \mathrm{Cu}, 0.98 \mathrm{ppm} \mathrm{Cr}$ and $44.87 \mathrm{ppm}$ Al. Water densities were $(\mathrm{c}=0,0,5$ i $10 \mathrm{mg} / \mathrm{l}), 992 \mathrm{~kg} / \mathrm{m}^{3}$ to $996 \mathrm{~kg} / \mathrm{m}^{3}$, viscosities $0.81 \cdot 10-6$ to $0.99 \cdot 10-6 \mathrm{~m}^{2} / \mathrm{s}$ and surface tension $76.2,64.8$ and $57.3 \mathrm{mN} / \mathrm{m}$, depending on added motor oil. Chemical method used for removal oxygen from water before adding of waste motor oil: $10 \mathrm{mg} / \mathrm{l} \mathrm{Na} \mathrm{SO}_{3}$ and $0,1 \mathrm{mg} / \mathrm{l} \mathrm{CoCl}{ }_{3} \cdot 6 \mathrm{H}_{2} \mathrm{O}$ [18], according to chemical equation:

$\mathrm{Na}_{2} \mathrm{SO}_{3}+\frac{1}{2} \mathrm{O}_{2} \stackrel{\mathrm{Co}^{+2}}{\longrightarrow} \mathrm{Na}_{2} \mathrm{SO}_{4}$.

The column was initially filled with previously prepared water ( $\mathrm{pH} 7.21-7.29)$, from which oxygen was extracted using a chemical method of introducing sodium-sulfite in the presence of a cobaltchloride hexa-hydrate catalyst. After that, a determined amount of waste oil was added into the water. Air flow regulation was performed using a flow regulator and relief valve until a set value for the applied analysis system was attained. 


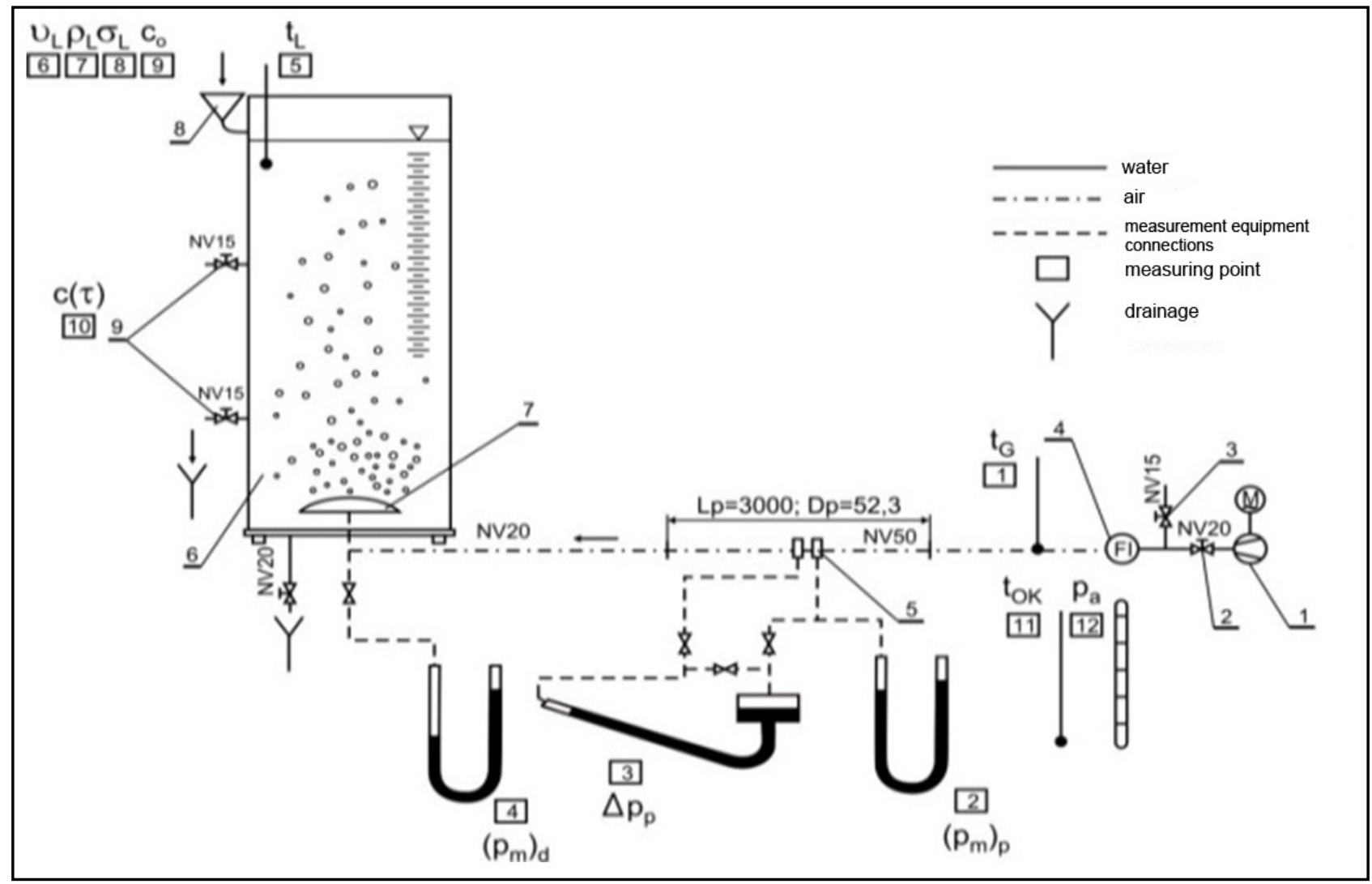

Figure 1: Scheme of experimental installation [18]

1 - low pressure compressor; 2 -air inflow pipe valve; 3 - relief valve; 4 - air flow regulator; 5 - air flow measuring orifice plate; 6 - column with corresponding connections and framework;

7 - disk-shaped membrane air distributor (HD 340, 0,06m²); 8 - water supply; 9 - sampling connection

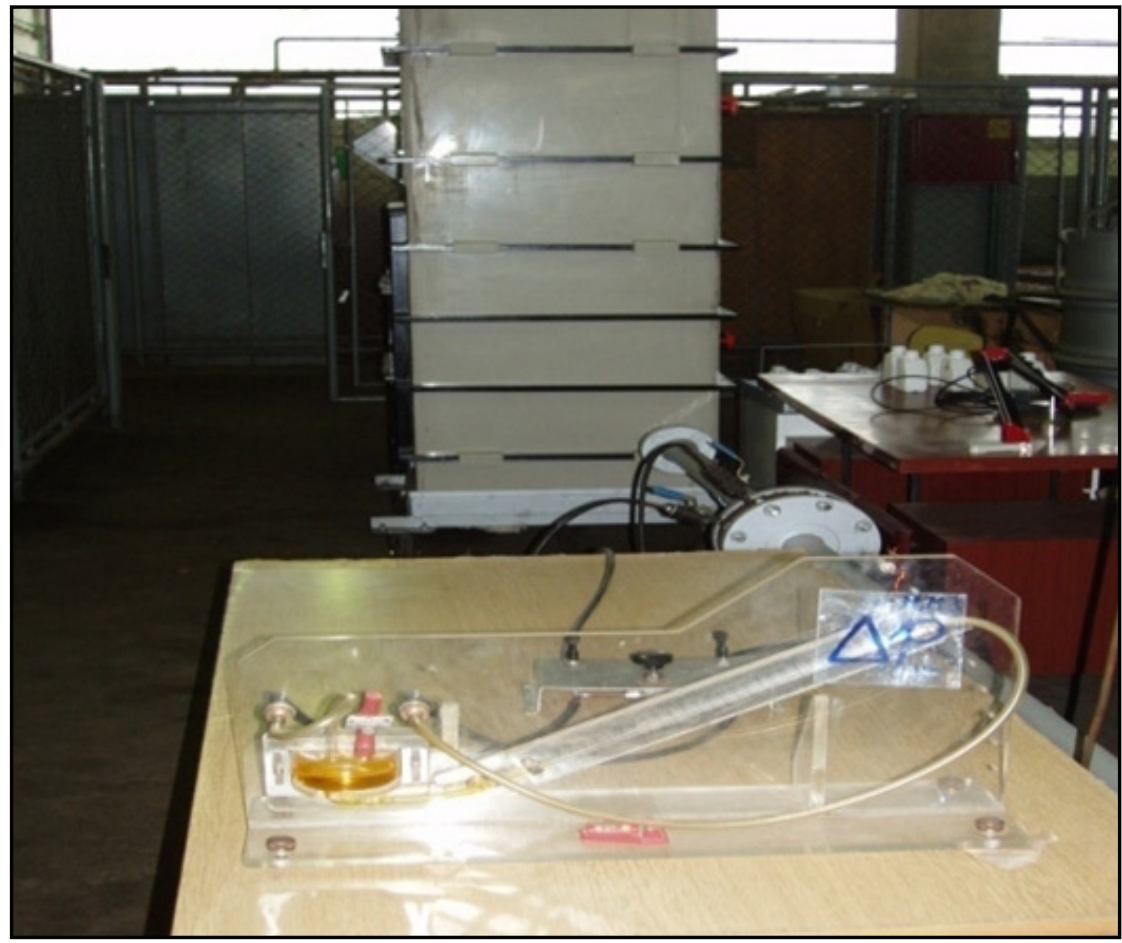

Figure 2: Eksperimental installation for examination of refinery waste water aeration parameters [18] 
When the flow is stabilized, water samples were taken from the column in equal time intervals starts $(\Delta \tau=60 \mathrm{~s})$.

The dissolved oxygen content was measured with HANNA instrument with membrane polarograph sensors (with accuracy $0,05 \mathrm{~g} / \mathrm{m}^{3}$ ) until the same value appeared three times,cs.

They define oxygen saturation degree:

$$
w_{s}=\frac{c_{s}}{c^{*}}
$$

It is calculated as the ratio with equilibrium Table data, $c^{*}$ caracteristical for clean water at measured stationary liquid temperature, according to Henry law.

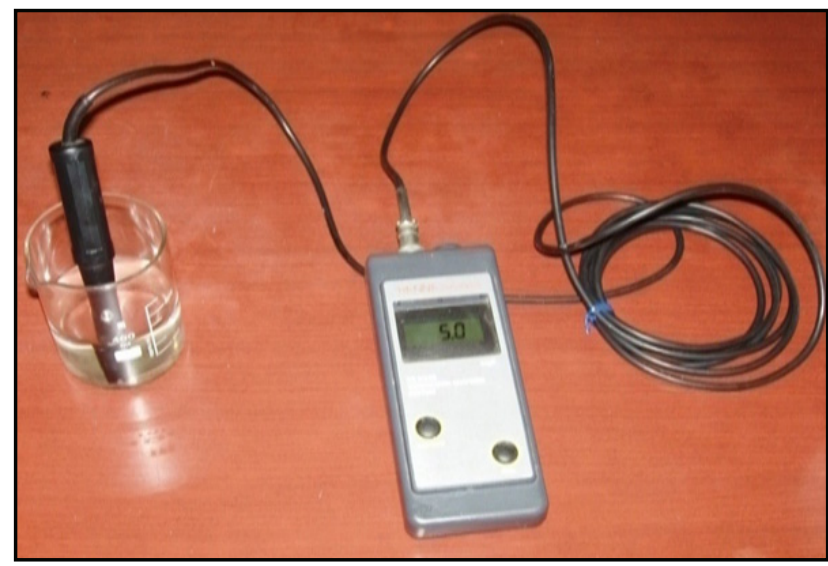

Figure 3: The measuring of oxygen content (HANNA, HI9142 instrument with polarographic sensor after previous calibration [18]

After one regime was analyzed, the compressor was switched off and the relief valve was opened completely. Water from the column was released into drains via a draining valve. The column was then filled with a fresh amount of water. Thus, the installation was ready for a new investigation regime, i.e. the described procedure was repeated.

\section{RESULTS AND DISCUSSION}

The calculated water vapor adsorption molar heat using Eq. (12), Joules-Thomson coefficients using Eq. (14), and oxygen saturation degree (Eq. 27), on the basis of the experimentally measured datas of air pressure and temperature at input and output as well as of the measured stationary oxygen content after saturation period [18] presents Table 1.

The results of comparison of water vapor adsorption molar heat with free energy of components enables the identification of active center, $\mathrm{K}$ with equal free energy, that present Figure 5 and Table 2, along with calculated water vapor accumulation calculated using Eq. (15) .

The influences of surface tension on water vapor adsorption molar heat present Figures 6, the influence of aeration system on the impurities concentration on water vapor accumulation up to final titration point present Table 3, and the functional dependence of oxygen saturation degree on the water vapor accumulation during condensation or vaporization presents Figure 7.

The resonance of water vapor adsorption molar heat and active centers free energy activate water vapor phase transformation in couple with catalyst vaporization, aggregation and specific adsorption (Table 2.):

The aeration systems influence to water vapor $\Delta_{f} G^{\theta}(K)_{a q}=\mp \sum \lambda_{\text {hydldeh }}^{\theta}$

accumulation:

a) negative values, $-\Delta$ cacc that indicate to condensation centers on the side of liquid phase:

- free energy of ammoniac prevents spontaneous dissolution and favor resonance oxygen free energy of endothermic dissolution (0-2-q)

- the couple of oxydation and hydrolysis of air component favor fast phases separation, i.e. nitrate solid salt hydration and sedimentation, $\mathrm{Ca}\left(\mathrm{NO}_{3}\right) 2 \cdot 2 \mathrm{H}_{2} \mathrm{O}(5-2-2$ and 5-2-6)

b) and to positive values, $+\Delta$ cacc that favor:

- hydrogen specific adsorption i.e., monolayer hydration of hydride anione (5-2-10, 5-1-q)

- and oxygen specific adsorption i.e., monolayer hydration of superoxide anione (10-2-q, 10-1- q)

Greater surface tension of aerated refinery wastewater containing hydrophilic components compared to clean water corresponds to the negative water vapor molar adsorption heat, that indicate to water vapor accumulation on condensation centers (0-2-q, 5-2-2 and 5-2-6).

Less surface tension of aerated refinery wastewater in containing hydrophobic components compared to clean water corresponds to the positive water vapor molar adsorption heat, that indicate to water vaporization centers ( $c-1-q)$.

The monitoring results of impurities concentrations indicate to its possible catalytic influence on water vapor accumulation up to impurity final titration point, depending on aeration system. 
Table 1. The eksperimental datas: air pressure at input in membrane distributor, $p$ and temperature, $T_{G}$ and at output from water column, $p_{a}$ and $T_{R}$, oxygen saturation degree, $w_{s}$ and calculated values:

Joules-Thomson coefficients, $\mu \mathrm{J}$.T. and water vapor adsorption molar heat, ${ }^{s} \Lambda_{\text {acc }}$ for the examined systems

\begin{tabular}{|c|c|c|c|c|c|c|c|}
\hline $\begin{array}{c}\text { System } \\
\mathbf{c - h}-\mathbf{q}\end{array}$ & $\begin{array}{c}\mathbf{p} \\
\mathbf{b a r}\end{array}$ & $\begin{array}{c}\mathbf{p}_{\mathbf{a}} \\
\mathbf{b a r}\end{array}$ & $\begin{array}{c}\mathbf{T}_{\mathbf{G}} \\
\mathbf{K}\end{array}$ & $\begin{array}{c}\mathbf{T}_{\mathbf{R}} \\
\mathbf{K}\end{array}$ & $\mathbf{w}_{\mathbf{s}}$ & $\begin{array}{c}\boldsymbol{\mu J} . \mathbf{T} \\
\mathbf{K} / \mathbf{b a r}\end{array}$ & $\begin{array}{c}\boldsymbol{\Sigma} \boldsymbol{\lambda}_{\text {acc }}^{\theta} \\
\mathbf{k J} / \mathbf{m o l}\end{array}$ \\
\hline $0-2-2$ & 1.2127 & 1.005 & 288.5 & 289 & 0.71 & -40.689 & $-16,09$ \\
\hline $0-2-6$ & 1.2392 & 1.005 & 290.6 & 290.5 & 0.72 & -40.689 & $-16,21$ \\
\hline $0-2-10$ & 1.3325 & 0.9981 & 291.7 & 287.2 & 0.76 & -40.689 & $-16,27$ \\
\hline $5-2-2$ & 1.2128 & 0.9981 & 286.5 & 285.5 & 0.63 & -0.5335 & -1219 \\
\hline $5-2-6$ & 1.2473 & 0.9981 & 287.3 & 288.2 & 0.63 & -0.5335 & -1222 \\
\hline $5-2-10$ & 1.0032 & 1.0026 & 286.4 & 288.3 & 0.68 & 9.137 & 71,14 \\
\hline $10-2-2$ & 1.2313 & 1.005 & 289.2 & 290.2 & 0.57 & 19.817 & 33,12 \\
\hline $10-2-5$ & 1.2631 & 1.005 & 290.4 & 292.1 & 0.58 & 19.817 & 33,26 \\
\hline $10-2-10$ & 1.3215 & 1.005 & 288.5 & 289 & 0.62 & 19.817 & 33,04 \\
\hline $5-1-2$ & 1.1355 & 1.0011 & 287.9 & 291.4 & 0.63 & 9.137 & 71,51 \\
\hline $5-1-6$ & 1.1701 & 1.0011 & 288.6 & 292 & 0.66 & 9.137 & 71,69 \\
\hline $5-1-10$ & 1.2444 & 1.001 & 288.8 & 292.9 & 0.66 & 9.137 & 71,74 \\
\hline $10-1-2$ & 1.13555 & 1.0011 & 291.25 & 291.4 & 0.57 & 14.638 & 44,64 \\
\hline $10-1-5$ & 1.1674 & 1.001 & 291.25 & 292.2 & 0.59 & 14.638 & 44,64 \\
\hline $10-1-10$ & 1.2444 & 1.001 & 290.25 & 293 & 0.58 & 14.638 & 44,64 \\
\hline
\end{tabular}

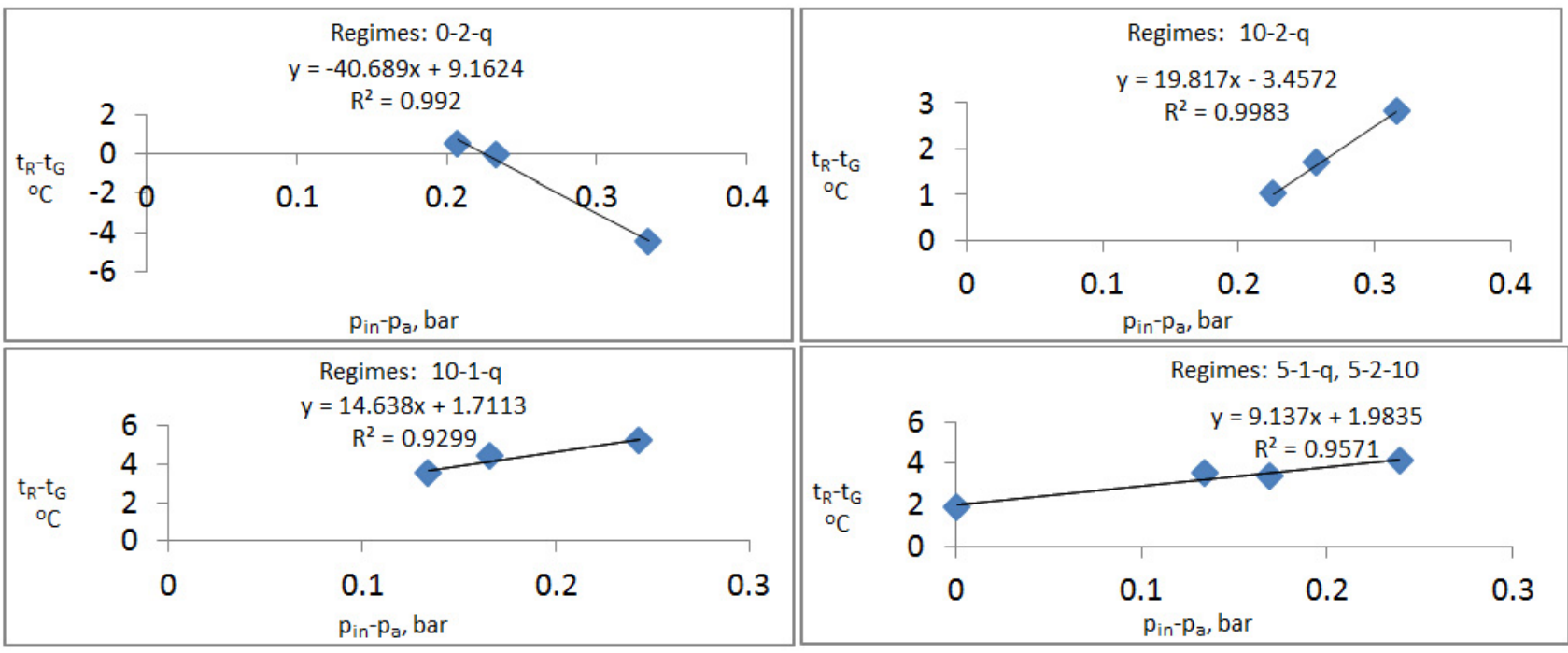

Figure 4: Linear functional dependences between pressure and temperature differences between input and exit, with the slope equal to the Joules -Thomson coefficient
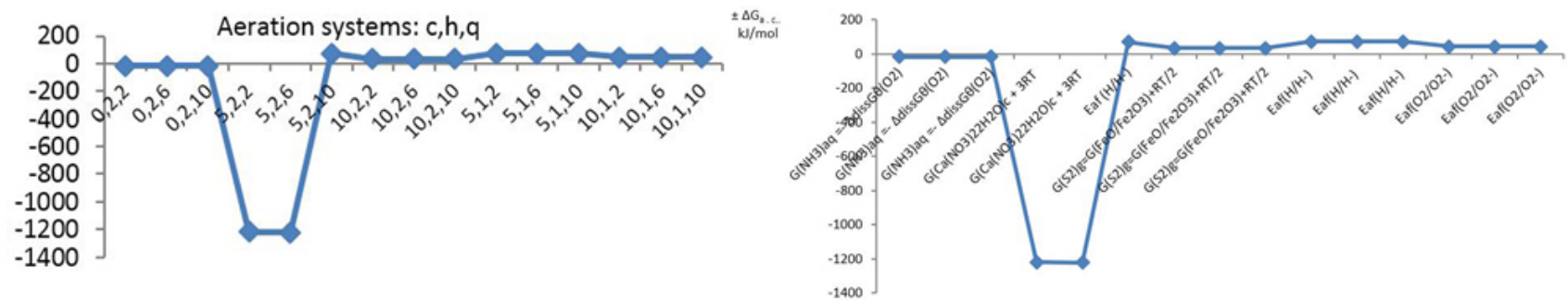

Figure 5: System influence to resonance activation of centers with free energy equal to water vapor adsorption heat 


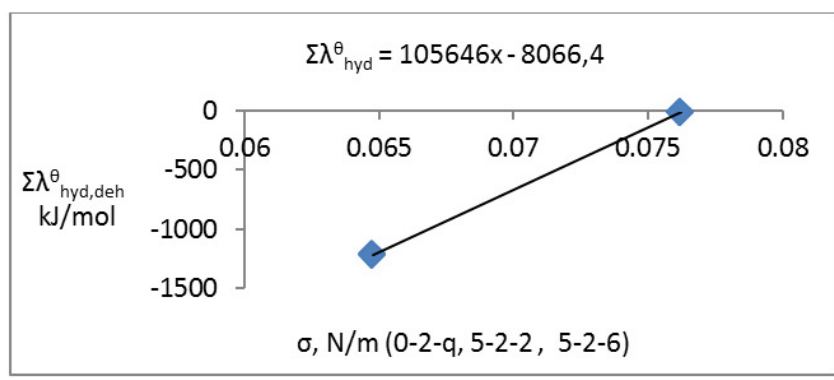

a)

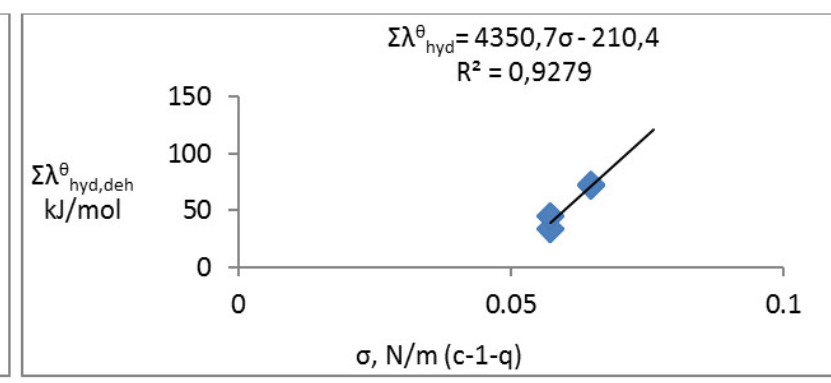

b)

Figure 6. Linear functional dependence of the molar adsorption water wapor heat on the water surface tension a) at the greater aerated water surface tension compared to clean water; $b$ ) and at the less aerated water surface tension compared to clean water

Table 2: Water vapor accumulation and resonance activated centers with free equal to water vapor molar adsorption heat

\begin{tabular}{|c|c|c|}
\hline $\begin{array}{l}\text { System } \\
\text { c-h-q }\end{array}$ & $\begin{array}{c}\Delta \mathrm{c}_{\mathrm{acc}} \\
\mathrm{mol} / \mathrm{m}^{3}\end{array}$ & $\begin{array}{c}\Delta_{\mathrm{f}} \mathrm{G}^{\theta} \text { a.c., } \\
\mathrm{kJ} / \mathrm{mol}\end{array}$ \\
\hline $0-2-2$ & -1.308 & $\Delta \mathrm{fG}^{\theta}\left(\mathrm{NH}_{3}\right) \mathrm{aq}=-\Delta \operatorname{dissG}^{\theta}\left(\mathrm{O}_{2}\right)$ \\
\hline $0-2-6$ & -1.464 & “ \\
\hline $0-2-10$ & -2.083 & " \\
\hline $5-2-2$ & -0.018 & $\Delta \mathrm{fG}^{\theta}\left(\mathrm{Ca}\left(\mathrm{NO}_{3}\right) 22 \mathrm{H}_{2} \mathrm{O}\right) \mathrm{c}+3 \mathrm{RT}$ \\
\hline $5-2-6$ & -0.021 & “ \\
\hline $5-2-10$ & 0.001 & $\mathrm{E}_{\mathrm{af}}(\mathrm{H} / \mathrm{H}-)_{\mathrm{aq}}$ \\
\hline $10-2-2$ & 0.692 & $\Delta \mathrm{fG}^{\theta}\left(\mathrm{S}_{2}\right)_{\mathrm{g}} \approx \Delta \mathrm{G}^{\theta}\left(\mathrm{O}_{2} / \mathrm{O}_{2}-\right)_{\mathrm{aq}}+\mathrm{RT} / 2$ \\
\hline $10-2-6$ & 0.786 & “ \\
\hline $10-2-10$ & 0.971 & “ \\
\hline $5-1-2$ & 0.190 & $\mathrm{E}_{\mathrm{af}}(\mathrm{H} / \mathrm{H}-)_{\mathrm{aq}}$ \\
\hline $5-1-6$ & 0.239 & “ \\
\hline $5-1-10$ & 0.338 & "“ \\
\hline $10-1-2$ & 0.305 & $\mathrm{E}_{\mathrm{af}}\left(\mathrm{O}_{2} / \mathrm{O}_{2}-\right)_{\mathrm{aq}}$ \\
\hline $10-1-6$ & 0.378 & “ \\
\hline $10-1-10$ & 0.552 & “ \\
\hline
\end{tabular}

The monitoring results of impurities concentrations indicate to water vapor accumulation up to final titration point of catalytic impurity, where:

$z \cdot \Delta c_{a c c}=\mp c_{i m p}$

- of hydrophilic component, $\mathrm{Na}_{2} \mathrm{CO}_{3}, \mathrm{CaCO}_{3}$ and some organic hydrophilic componunds, measured as COD ( 0-2-q)

- of [Na+] from [Na2SO3] ( 5-2-2 and 5-2-6)

- of $\mathrm{Fe}$ and $\mathrm{Fe} / \mathrm{Cu}$ alloy (5-2-10)

- of nitrogen compounds (10-2-q)

- of microorganisms (5-1-2 and 5-1-6)

- of organic compounds with $\mathrm{N}$ hetero atom $(5-1-10,10-1-q)$
The obtained diagnostic results verify the linear functional dependence (Figure 7, Eq. 29) of oxygen saturation degree on accumulated water vapor that control the slowest successive relaxation step, i.e. oxygen distribution between equilibrium and stationary energy level ( see Eq. 30 to Eq. 33.).

$$
w_{s}=-0.0581 \cdot \Delta c_{a c c}+0.6376
$$

$\left(\mathrm{R}^{2}=0.7667\right)$

The experimental obtained value of oxygen saturation degree (see Eq. 27) is indicator of vibration energy of specifically chemisorbed oxygen in crystal lattice, that influence to over-potential and mechanism of oxygen slowest successive relaxation step and controls oxygen distribution between stationary and equilibrium energy states [03]:

$F \eta=\left(E_{s}-E^{*}\right)_{K O 2 a q}=R T$

a) increased oxygen concentration gradient between equilibrium state in accumulated clean water on condensation centers and stationary state in saturated wastewater indicate to the successive slowest distribution step, thermal collisions on the side of gas phase, acc. Boltzmann distribution law, dominant in the gas oxygen distribution mechanism between two energy levels (0-2-q) :

$\frac{c_{s}}{c^{*}}=\frac{1}{e^{-\Delta E / R T}+1}=0.73$

b) decreaseg oxygen concentration gradient due to the fast phase separation indicate to diffusion as the dominant step in the slowest successive oxygen distribution between equilibrium and stationary state(5-2-2 and 5-2-6):

$$
\frac{c_{s}}{c^{*}}=1-\mathrm{e}^{-\mathrm{F} \eta_{\mathrm{d}} / R T}=0.63
$$


Table 3: Impuritiy concentration in refinery wastewater, $c_{i m}$ activated in water vapor accumulation, $\Delta c_{\text {acc }}$ up to final titration point, depending on aeration system, $c-h-q$

\begin{tabular}{|c|c|c|c|c|c|c|}
\hline $\begin{array}{l}\text { Impurity in aer. } \\
\text { water }[18,20]\end{array}$ & $\begin{array}{c}\mathrm{c}_{\mathrm{im} \cdot}, \\
\text { Novem. } \\
\mathrm{mol} / \mathrm{m}^{3}\end{array}$ & $\begin{array}{c}\mathrm{c}_{\text {im }}, \\
\text { Decem. } \\
\mathrm{mol} / \mathrm{m}^{3}\end{array}$ & $\begin{array}{l}\mathrm{c}_{\mathrm{im} \cdot}, \\
\text { Jan. } \\
\mathrm{mol} / \mathrm{m}^{3}\end{array}$ & $\begin{array}{c}c_{i \mathrm{im}}, \\
\text { Feb.Marc } \\
\mathrm{mol} / \mathrm{m}^{3}\end{array}$ & $\mathrm{Z} \Delta \mathrm{c}_{\mathrm{acc}}=+/-\mathrm{C}_{\mathrm{imp}} \mathrm{ol} / \mathrm{m}^{3}$ & $\begin{array}{c}\text { System } \\
\text { C-h-q }\end{array}$ \\
\hline $\begin{array}{c}\mathrm{CaCO}_{3}, \text { or } \mathrm{NaOH} \\
=\mathrm{f}(\mathrm{m} \text {-alcality })\end{array}$ & 3.8 & 4 & 3.76 & 3.64 & $2 \cdot \Delta c_{\text {acc }}=-3.8$ & $0-2-10$ \\
\hline $\mathrm{CO}_{3}^{2-=}=\mathrm{f}(\mathrm{m}$-alcality $)$ & 1.9 & 2.0 & 1.88 & 1.82 & $\Delta c_{\text {acc }}=-1.9$ & $0-2-10$ \\
\hline COD & 1.0 & 1.8 & 1.6 & 2.1 & $\Delta \mathrm{c}_{\mathrm{acc}}=-(1.6 \pm 0.3)$ & $0-2-(2,6)$ \\
\hline $\begin{array}{c}{\left[\mathrm{Na}^{+}\right] \text {from }} \\
{\left[\mathrm{Na}_{2} \mathrm{SO}_{3}\right]}\end{array}$ & 0.02 & 0.02 & 0.02 & 0.02 & $\Delta c_{\text {acc }}=-0.02$ & $5-2-(2,6)$ \\
\hline $\mathrm{Fe}$ & 0,0012 & 0,00063 & 0,0009 & 0,00089 & $\Delta \mathrm{c}_{\mathrm{acc}}=0.001$ & $5-2-10$ \\
\hline $\mathrm{Cu}$ & 0,000156 & 0,000468 & & & $\Delta \mathrm{c}_{\text {acc }} / 2=0.0005$ & $5-2-10$ \\
\hline $\mathrm{N}$ & 0.59 & 0.71 & 0.63 & 0.95 & $\Delta \mathrm{c}_{\mathrm{acc}}=(0.81 \pm 0.22)$ & $10-2-q$ \\
\hline BOD & & & & 0.23 & $\Delta c_{\text {acc }}=0.23$ & $5-1-(2,6)$ \\
\hline $\begin{array}{l}\mathrm{N} \text { in prim. pur. } \\
\text { water }\end{array}$ & 0.46 & 0.26 & 0.27 & 0.33 & $\Delta \mathrm{c}_{\mathrm{acc}}=(0.33 \pm 0.14)$ & $10-1-q$ \\
\hline
\end{tabular}

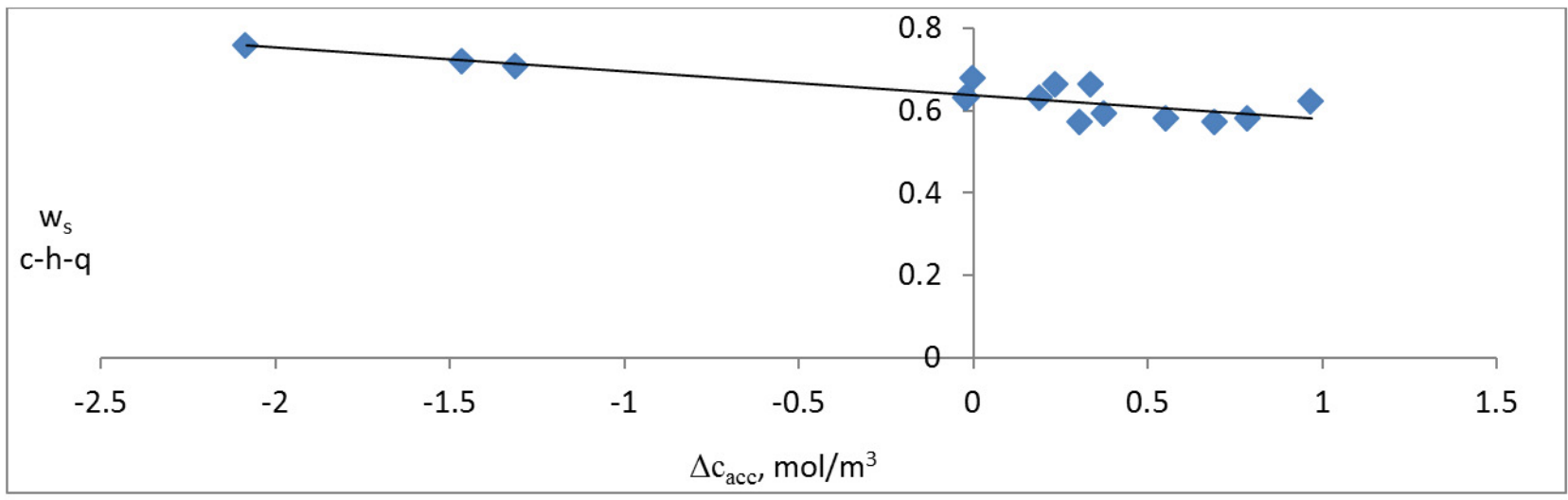

Figure 7: Linear functional dependence between accumulated water vapor concentration change, $\Delta c_{\text {acc }}$ and oxygen saturation degree $w_{s}$, for the all 15 examined regimes, $c-h-q$

c) vaporization of hydrated specific adsorbed hydrogen influences to oxygen saturation degree corresponding to the half of the sum defined for the both mechanisms describe $\mathrm{Eq},(31)$ and $\mathrm{Eq},(32)$, on the side of gas and liquid phase (5-2-10 and 5-1-q):

$\frac{c_{s}}{c^{*}}=\frac{0.73+0.63}{2}=0.68$

d) vaporization of hydrated specific adsorbed oxygen influences to oxygen saturation degree corresponding to the half of the sum defined with the oxygen diffusion describe Eq. (32) and reversible electron titration at standard potential of corrosion indicator, where $c / c^{*}=0.5(10-h-q)$ :

$$
\frac{c_{s}}{c^{*}}=\frac{0.5+0.63}{2}=0.565
$$

\section{CONCLUSION}

The conclusion remarks are as the follows:

- The electromotor and compressor work in molar oxygen transfer keep stationary water vapor critical pressure, that influence to cataIytic couple of prevented exothermic hydration and favored endothermic processes, according to II law of thermodynamic

- The proposed diagnostics method of water vapor adsorption heat confirm the obtained liner functional dependence between water vapor catalytic accumulation and experimental determined oxygen saturation degree , as indicator of proper process condition

- The diagnostics results of water vapor adsorption heat and catalytic accumulation in oxygen saturation period indicate to mecha- 
nism of oxygen distribution between equilibrium and stationary state in the slowest relaxation step in zone of condensation, denitrification/nitrification, aggregation/sedimentation and vaporization on surfactants

- The obtained results can be useful in developing of methods that control membrane fouling and scalling along with choose of optimized regime.

\section{REFERENCES}

1) Armellini F.J., Tester J.W., Hong G.T. (1994): Precipitation of sodium chloride and sodium sulfate, in water from sub to supercritical solution, Journal of Supercritical Fluids, Vol. 7 , pp. $147-157$

2) Bard, A., Parsons, R., Jordan, J. (1983): Standard electrochemical potentials in aqueous solutions, JUPAC ed, New York, Basel

3) Marshal W.L., Franck, E.U.( 1981): Ion product of water substance, J. Phys. Chem. Ref. Data vol. 10, Vol. 2, pp. 295

4) Ševaljević, M., Simić, S., and Ševaljević, P. (2012): Thermodynamic diagnostic of electron densities in gas bubbles in aerated saturated refinery waste water, Desalination and Water Treatment, Vol. 421, Nb. 1-3, pp. 144-154

5) Connoly J.F. (1966): Soluibility of hydrocarbon in water near the water critical temperatures, J. Chem.Eng. Data, Vol. 11, Nb. 1, pp. 13-16

6) Egan-Benck, K. O., Mc Carty and Winkler, W.( 1993):Choosing diffusers, Water Environment and Technology, Vol. 5, Nb. 2, pp. 54-59

7) Heger K, Uematsu M. Franck, E.U. (1980): The static dielectric constant of water at high pressures and temperatures, Ber, Bunseges. ,Phis. Chem., Vol. 84, pp. 758

8) http://www.aesarabia.com/hydrothermal-hydrolysis-systems/AES

9) Japas, M.L. , Franck, E.U. (1985): High pressure phase equilibria and PVE data of the water - oxygen system including water-air to $672 \mathrm{~K}$ and $290 \mathrm{MPa}$, Ber, Bunseges. Phis. Chem., Vol. 89. pp. 1268-1275

10) Josephson, J. (1982): Supercritical Fluids, Environ.Sci Technol. Vol. 16, Nb. 19, pp. 548A -551A
11) Ševaljevic, M., Stanojevic, M., Simić, S., Ševaljevic, M., (2014): Water entropy-driven electrochemical relaxation of dissolved oxygen in aerated refinery wastewater, Desalination and Water Treatment, Vol. 52, Nb. 16-18, pp. 3035-3046

12) Ševaljević, M., Stanojević, M., Simić, S., Pavlović, M. (2009): Thermodynamic study of aeration kinetic in treatment of refinery wastewater in bio-aeration tanks, Desalination, Vol. 248, Nb, 1-3, pp. 941- 960

13) Simić, S., Ševaljević , M., Stanojević, M., Ševaljević, P.(2014): Thermodynamic diagnostics of the depolarization overpotential and electron temperatures of contact surfaces in aerated refinery waste water, Desalination and Water Treatment, Vol. 52 , Nb. 3739, pp. 7065-7081

14) Simić, S. (2006) Influenceof aeration regimes on processes efficiency in biology treatment of refinery waste water, Doktoral thesis , Mechanical engineering faculty, University in Belgrade

15) Stanojevic. M., Ševaljevic, M., Simic. S., Ševaljevic, M. (2013): Influence of the water height in aeration regimes with the same membrane diffuser on technical characteristics of aeration system, Desalination and Water Treatment, Vol. 51, Nb. 22-24, pp. 4271-4282

16) Todheide, K. (1972): Water at high temperatures and pressures and low viscosity, A comprehensive Treatise, F. Franks, ed. New York

17) U.S.EPA ( 1999): Water Technology Fact Sheet, Fine Bubble Aeration EPA-832-F-99-065

18) Weidenbach, G. , Furst, H. (1963): Chem. Techn., Vol.15, pp. 589

Paper sent to revision: 13.07.2015.

Paper ready for publication: 25.11.2015. 